SHORT REPORT

\title{
Not all cases of neck pain with/without torticollis are benign: unusual presentations in a paediatric accident and emergency department
}

\author{
A Natarajan, J G Yassa, D P Burke, J A Fernandes
}

Emerg Med J 2005;22:646-649. doi: 10.1136/emj.2004.015586

$\mathrm{N}$ eck pain in children is not an uncommon presenting complaint in a paediatric accident and emergency department. Sheffield has a population of approximately 97000 children of whom 33874 attended the accident and emergency department at the children's hospital in a one year period from 1998 to 1999. Of these, about 817 had pain in the neck region as part of their presenting complaint.

Neck pain in adults is often a manifestation of degenerative disease of the spine whereas in children the commonest causes are trauma and infections. There are other less common but more sinister underlying causes of neck pain. The aim of this paper is to highlight these unusual conditions which present as neck pain.

Most junior doctors term muscular spasm in the neck region as torticollis. Not all kinds of unusual neck posturing and pain, however, are due to torticollis and not all cases of torticollis are benign. ${ }^{12}$ This differentiation is important in the clinical work up of these patients.

We describe five patients who attended the accident and emergency department at our hospital with a presenting complaint of neck pain. These cases highlight the importance of careful evaluation of neck pain in children to prevent delay in diagnosis of less common but more serious underlying conditions. The clinical features in the history and/or examination which should raise suspicion of a less benign cause of the neck pain are highlighted with an asterix $\left({ }^{*}\right)$.

\section{CASES}

\section{Patient 1}

A 6 year old boy presented with neck pain of sudden onset and restricted neck movement. He was unable to localise the exact site of the pain. There was no history of trauma, systemic upset, or any neurological symptoms prior to the onset of the pain. On examination he held his neck flexed and had restriction of all movements. Systemic examination including neurological examination revealed normal findings. An initial diagnosis of torticollis due to muscle spasm was made. On review in the orthopaedic clinic four days later, his neck pain had worsened* and he held his neck fixed in hyperflexion such that his chin was touching the chest ${ }^{*}$. Clinical examination was unremarkable except for the abnormal neck posture. Plain $x$ rays of the cervical spine showed normal findings. A magnetic resonance imaging (MRI) scan revealed a large intramedullary tumour in the cervical and upper thoracic region from $\mathrm{C} 1$ to $\mathrm{T} 2$ (fig 1).

\section{Patient 2}

A 5 year old child presented with general malaise and neck and back pain of two days' duration. Initial examination revealed neck tilt to the left and a kyphotic posture of his upper torso. He responded to ibuprofen and though the abnormal neck posture persisted he could straighten his

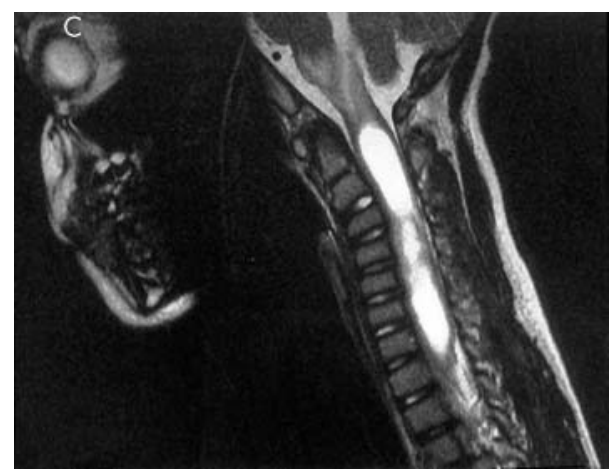

Figure $1 \mathrm{Tl}$-weighted MRI scan of the cervical spine showing a large intramedullary tumour in the cervical and upper thoracic region $\mathrm{Cl}-\mathrm{C} 5$.

back. A presumptive diagnosis of torticollis due to muscle spasm was made and a review appointment arranged in four days time. On this visit he appeared visibly distressed* with a pain score of $8 / 10(1=$ pain free; $10=$ most painful $)$ and anxious and had a pronounced stoop with hips held in flexion and neck tilted to the left*. He refused to flex his neck but rotated it laterally. Initial investigations including full blood count, C-reactive protein and $x$ rays of cervical and thoracolumbar spine revealed normal findings. Further imaging including an ultrasound scan of the abdomen and computed tomography (CT) scan of cervical spine also had

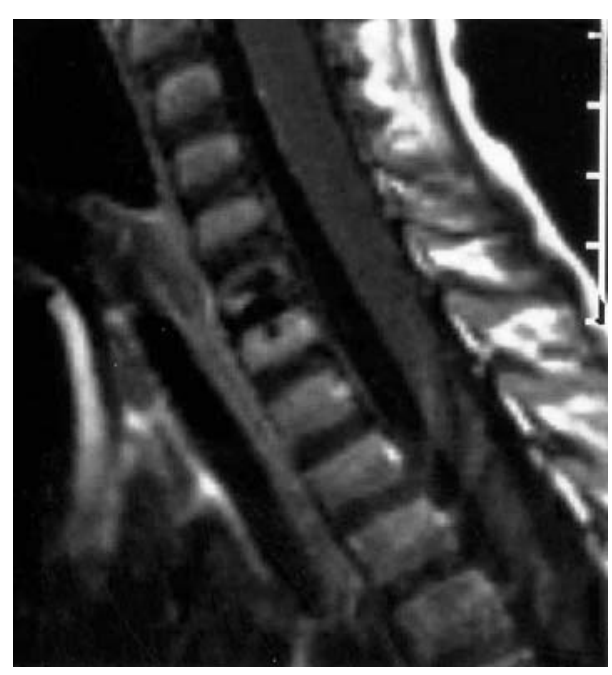

Figure $2 \mathrm{Tl}$-weighted MRI scan of the cervical spine showing discitis involving $\mathrm{C} 6 / \mathrm{C} 7$ disc. 


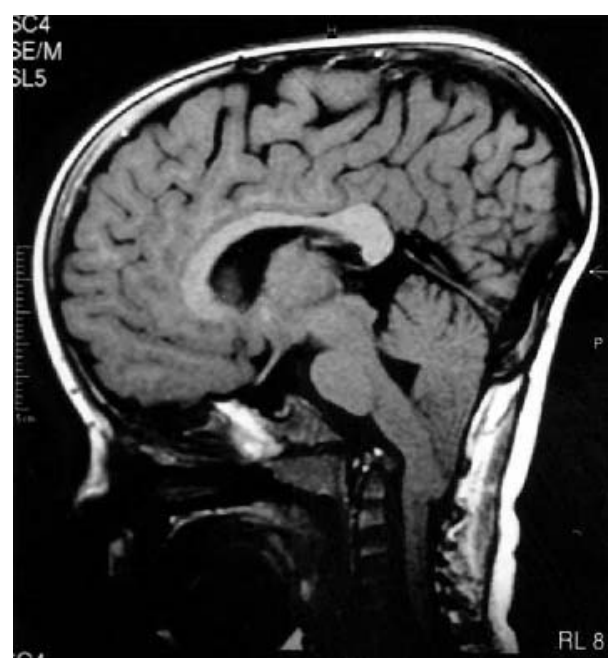

Figure $3 \mathrm{Tl}$-weighted MRI scan of the brain and craniocervical junction showing a Chiari-type malformation.

normal findings. An MRI scan of cervical spine showed discitis involving C6/C7 disc (fig 2).

\section{Patient 3}

A 2 year old boy presented with symptoms of upper respiratory tract infection and pain in his neck. No obvious cause of this could be identified, that is inflamed pharynx or tonsillitis. In view of his young age* at presentation and no obvious cause for the pain identified on preliminary investigation (plain $x$ ray head and neck), further investigations were arranged. A CT scan of head and neck showed marked abnormality of the posterior aspect of base of skull with abnormal fusion of the posterior aspect of the foramen magnum. He was referred to neurosurgery and an MRI scan showed complex abnormality of craniocervical junction with a possible cranium bifidum (fig 3 ). The child had by now started complaining of headaches of increasing frequency and severity. Currently he is under regular follow up with the option of surgical intervention should this be indicated.

\section{Patient 4}

A 4 year old girl presented with a history of intermittent neck pain since a few months. Previous episodes had settled spontaneously without any treatment and she had not been referred to the hospital. On this occasion the pain had commenced on waking* in the morning and lasted through most of the day*. There was no history of recent or past trauma and she was otherwise fit and well, with no obvious cause for the pain. On examination, there was nothing abnormal other than mild stiffness of the neck. She had a full range of neck movements and no abnormal neck posturing. Due to the recurring* nature of the pain and its spontaneous onset on waking*, it was felt that baseline investigations should be done. Plain radiographs of the cervical spine showed unusual calcification at C4-C5 disc level (this is an unusual but well recognised cause of neck pain in children, with $70 \%$ of the calcifications seen in the cervical region. The aetiology of this in children is unknown and patients typically present with pain, decreased range of movements and torticollis). An MRI scan confirmed this to be intradiscal calcification (fig 4). Her symptoms settled with non-steroidal anti-inflammatory drugs.

\section{Patient 5}

An 8 year old child presented with neck pain and restriction of terminal neck movement, predominantly rotation. She had

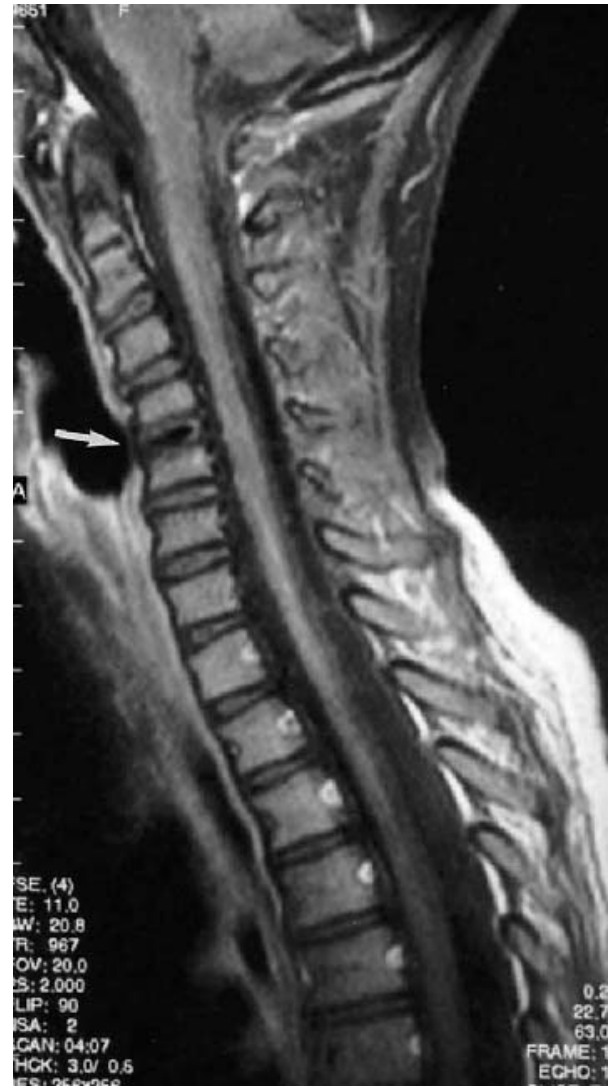

Figure 4 T2-weighted cervical spine MRI scan showing calcification of intervertebral disc between C4 and C5 (arrow).

a history of intermittent neck pain for the past two years, which had been ignored by the parents. On this occasion however the pain was more acute in onset and of an increased intensity ${ }^{*}$. Once again, as in patient 4 , due to the recurring ${ }^{*}$ nature of the pain, its increasing intensity, and no obvious cause elucidated from either the history or the examination, further investigations were requested. Blood tests including rheumatological profile were normal. Cervical spine anteroposterior and lateral views showed normal findings. An open mouth view $x$ ray of the cervical spine showed osteophyte-like excrescence at the C1-C2 articulation (fig 5) suggesting a possible enthesopathy. Symptoms persisted but with no systemic or joint involvement. A rheumatology opinion was requested but no confirmatory diagnosis has been made. We presume her symptoms are related to the abnormal articulation or may be an early manifestation of an enthesopathy.

\section{DISCUSSION}

Neck pain is a common problem encountered in paediatric accident and emergency departments, requiring exclusion of serious underlying pathology and decisions regarding the extent of work up needed. The pain may or may not be associated with an acquired torticollis. Torticollis (Latin word meaning "twisted neck") is tilting and rotation of the head to one side with restricted rotation towards the other side. It is a symptom of cervical spine abnormality. ${ }^{3-5}$ Neck pain may be associated with neck deformities such as torticollis, kyphosis, or a shortened neck and/or with symptoms of neurological compromise and systemic illness. ${ }^{4}$ The more common causes $^{3467}$ of neck pain include: 


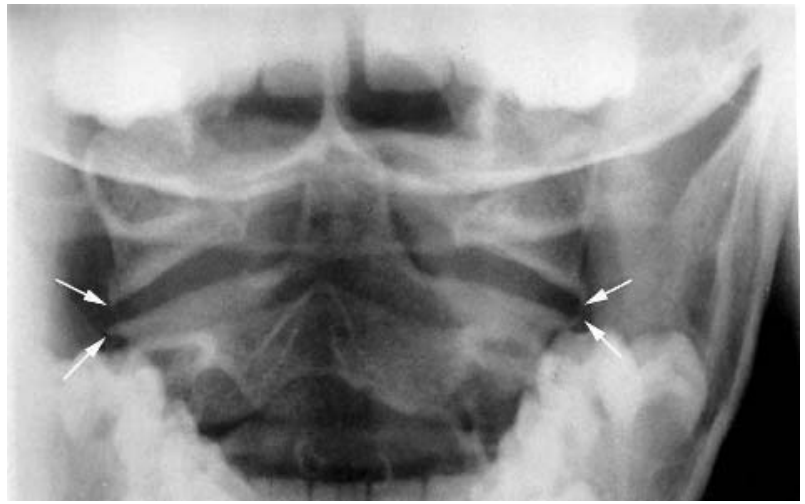

Figure 5 Open mouth view $x$ ray of the cervical spine showing osteophyte-like excrescence at $\mathrm{Cl}-\mathrm{C} 2$ articulation (arrows).

- infections ${ }^{89}$ (meningitis, pneumonia, otitis media, tonsillitis, cervical adenitis, retropharyngeal abscess, mumps, and cerebral abscess)

- trauma

- ophthalmological conditions ${ }^{3}{ }^{4}$ such as squint.

The less common causes include:

- juvenile chronic arthritis ${ }^{10}$

- Arnold-Chiari malformations ${ }^{11}$

- posterior fossa and cervical spinal tumours ${ }^{12}$

- vertebral anomalies

- cervical osteomyelitis

- spondyloarthropathies

- myositis ossificans progressiva.

Some conditions presenting with both neck pain and torticollis include trauma, infections, tumours ${ }^{13-15}$ (spinal cord and head and neck tumours), calcified intravertebral disc $^{16}$ and Sandifer's syndrome. ${ }^{17}{ }^{18}$

In most patients presenting with neck pain a cause for this is easily identifiable. However, in the few that it is not obvious, follow up and further investigations may be needed to reach a diagnosis. We suggest that a detailed history covering the points listed in box 1 should be taken from all children presenting with neck pain. Presence of any of these features either in the history or on clinical examination should act as a warning sign for further investigation and or follow up of these patients to help differentiate between a benign and more sinister cause of the neck pain.

A complete physical examination should include examination of the neurological system, spine, and eyes especially eye movements and the cover-uncover test. ${ }^{71}$ If then an initial diagnosis of muscular spasm is made the child should be asked to return for follow up in 48-72 hours should the pain persist. A second clinical examination may give more clues and more appropriate imaging modalities can be used.

The basis of a proper clinical diagnosis remains the patient's history and physical examination. Unusual presentation with neck pain, abnormal neck posturing, gait abnormalities and its persistence should ring a warning bell for other potentially less common but more sinister diagnoses. The examiner's index of suspicion is crucial to the completeness of work up of patients with neck pain with/ without torticollis. With easy access to imaging modalities, conditions like intracranial tumours of the base of skull, intraspinal tumours, congenital abnormalities, and spinal infections can be easily diagnosed and early treatment instituted.
Box 1: Neck pain. Points to cover in history and examination

- Time of onset of pain (spontaneous onset at night or night pain)

- Any associated trauma

- Any relieving or exacerbating factors

- Pain in the occipital condyle (seen in posterior fossa tumours)

- Score the pain on available pain charts

- Duration of pain, whether continuous or intermittent

- Interference with daily activity

- Any history of drugs especially those causing extrapyramidal side effects

- Problems with vision

- Other associated symptoms like headaches, vertigo, vomiting

- Unusual neck posturing, that is, hyperflexed position, child trying to splint the neck with their hands. These should raise the suspicion of posterior fossa tumours, discitis and spinal cord tumours

- Any gait abnormalities (base of skull tumour and spinal cord tumours) and repeated attendances at the hospital with persistence of symptoms

This series of unusual and rare case reports highlights that physicians in the paediatric accident and emergency department need more awareness when dealing with children with neck pain and abnormal neck posturing. A search for atypical features of neck pain and abnormal neck posture should avoid delays in diagnosis and appropriate referral and management.

\section{Authors' affiliations}

A Natarajan, Department of Child Health, Sheffield Children's Hospital, Sheffield, UK

J G Yassa, D P Burke, Department of Accident and Emergency, Sheffield Children's Hospital, Sheffield, UK

J A Fernandes, Department of Paediatric Orthopaedics and Trauma Surgery, Sheffield Children's Hospital, Sheffield, UK

Competing interests: none declared

Correspondence to: A Natarajan, Lecturer in Child Health, Sheffield Children's Hospital, Sheffield, S10 2TH, UK; a.natarajan@shef.ac.uk

Accepted for publication 18 June 2004

\section{REFERENCES}

1 Nemet D, Gottesman G, Pomeranz A, et al. Acute acquired non-traumatic torticollis in hospitalized children. Harefuah 2002;141:519-21.

2 Ballock RT, Song KM. The prevalence of nonmuscular causes of torticollis in children. J Pediatr Orthop 1996;16:500-4.

3 Kuppermann N. Neck stiffness. In: Fleisher GR, Ludwig S, eds. Textbook of Pediatric Emergency Medicine, 4th edn. Philadelphia, PA: WB Sanders, 2000:391-9.

4 Disorders of the Neck. In: Herring JA. Tachdijan's Pediatric Orthopaedics, 3rd edn. Philadelphia, PA: WB Sanders, 2002:171-212.

5 Kahn ML, Davidson R, Drummond DS. Acquired torticollis in children. Orthop $\operatorname{Rev} 1991 ; 20: 667-74$.

6 Gennuso R. Cervical pain in children. Mt Sinai J Med 1994;61:212-17.

7 Sherk HH, Watters WC, Zeiger L. Evaluation and treatment of neck pain. Orthop Clin North Am 1982;13:439-52.

8 Craig FW, Schunk JE. Retropharyngeal abscess in children: clinical presentation, utility of imaging, and current management. Pediatrics 2003;111(6P+1):1394-8.

9 Wang LF, Kuo WR, Tsai SM, et al. Characterizations of life threatening deep cervical space infections: a review of one hundred ninety-six cases. Am J Otolaryngol 2003;24:111-17. 
10 Fried JA, Athreya B, Gregg JR, et al. The cervical spine in juvenile rheumatoid arthritis. Clin Orthop 1983;179:102-6.

11 Greenlee JD, Donovan KA, Hasan DM, et al. Chiari I malformation in the very young child: the spectrum of presentations and experience in 31 children under age 6 years. Pediatrics 2002;110:1212-19.

12 Antunes NL. Back and neck pain in children with cancer. Pediatr Neurol 2002;27:46-8.

13 Visudhiphan P, Chiemchanya S, Somburanasin R, et al. Torticollis as the presenting sign in cervical spine infection and tumour. Clinical Pediatr 1982;21:71-6.

14 Constantini S, Houten J, Miller DC, et al. Intramedullary spinal cord tumours in children under the age of 3 years. J Neurosurg 1996;85:1036-43.
15 Raskas DS, Graziano GP, Herzenberg JE et al Osteoid osteoma and osteoblastoma of the spine. J Spinal Disord 1992;5:204-11.

16 Causey AL, Evans OB, Lewis-Abney K. Intervertebral disk calcification: an unusual cause of acquired torticollis in childhood. Pediatr Emerg Care 1996;12:356-9.

17 Murphy WJ, Gellis SS. Torticollis with hiatus hernia in infancy: Sandifer syndrome. Am J Dis Child 1977;131:564-5.

18 Ramenofsky ML, Buyse M, Goldberg MJ, et al. Gastroesophageal reflux and torticollis. J Bone Joint Surg 1978;60:1140-1.

19 Rosenberg NM, Kost S, Dowd MD, et al. The passive and aggressive evaluation of the cervical area. Pediatr Emerg Care 1998;14:305-9.

Three day in depth analysis into prehospital aspects of accidents, incidents, and disasters.

23 to 25 September 2005, Moat House Hotel, Nottingham, UK

A one day symposium on the mechanism of injury to vehicle occupants in road traffic crashes. With original research and the knowledge of world renowned experts.

The practical realities of major incidents. Contemporary experiences and challenging training scenarios you can participate in. The Heywood Memorial Lecture \& BASICS AGM.

Compound and uncompensated disasters the UK could face. A realistic appraisal of Britain's ability to cope. Defining the Immediate Care Practitioner and debating their role.

For further details and information please contact; BASICS, Turret House, Turret Lane, Ipswich IP4 1DL; tel: 08701654 999; email: admin@basics.org.uk 


\section{PostScript}

\section{CORRECTIONS}

doi: 10.1136/emj.2004.015586corr l

In the short report titled, Not all cases of neck pain with/without torticollis are benign: unusual presentations in a paediatric accident and emergency department (Emerg Med J 2005: 22:645-8) two errors have occurred. The corresponding address for A Natarajan is incorrect and should be Consultant Paediatrician, anatarajan@hotmail.com. The second error is in the legend for figure 1. It should read ' $\mathrm{Tl}$-weighted MRI scan of the cervical spine showing a large intramedullary tumour in the cervical and upper thoracic region C1-T2.' The journal apologises for these errors.
An author's error occurred in the paper titled Hazardous drinkers in the accident and emergency department-Who accepts advice? (Emerg Med J 2004;21:491-2). Incorrect proportions for 'Believed initial AED attendance related to drinking' appear in table $\mathrm{l}$ (A). The figures were calculated using a denominator based on the number of responses to that item, rather than the number of patients who were offered advice. The correct proportions are 49.9 for 'Accepted advice' and 45.9 for 'Did not accept advice' (not 70.1 and 69.8 as stated in the text). The difference in proportion $(95 \% \mathrm{CI})$ should read $4.0(-2.1$ to $10.1)$.
In the paper titled, Comparison of the effectiveness of intravenous diltiazem and metoprolol in the management of rapid ventricular rate in atrial fibrillation (Emerg Med J 2005;22:41 1-4) an error has occurred in table 4 . At 20 minutes, places of systolic and diastolic pressures were exchanged. The author apologises for this error.

doi: 10.1136/emj.2005.002005

In part 15 of the $\mathrm{ABC}$ of community emergency care (Emerg Med J 2005;22 564-71) the legend for figure 2 is incorrect. It should read 'Sixth nerve palsy right eye: failure of abduction. Courtesy of Dr P Marazzi/SPL model released'.

\section{Clinical Evidence-Call for contributors}

Clinical Evidence is a regularly updated evidence-based journal available worldwide both as a paper version and on the internet. Clinical Evidence needs to recruit a number of new contributors. Contributors are healthcare professionals or epidemiologists with experience in evidence-based medicine and the ability to write in a concise and structured way.

Areas for which we are currently seeking authors:

- Child health: nocturnal enuresis

- Eye disorders: bacterial conjunctivitis

- Male health: prostate cancer (metastatic)

- Women's health: pre-menstrual syndrome; pyelonephritis in non-pregnant women However, we are always looking for others, so do not let this list discourage you.

Being a contributor involves:

- Selecting from a validated, screened search (performed by in-house Information Specialists) epidemiologically sound studies for inclusion.

- Documenting your decisions about which studies to include on an inclusion and exclusion form, which we keep on file.

- Writing the text to a highly structured template (about 1500-3000 words), using evidence from the final studies chosen, within 8-10 weeks of receiving the literature search.

- Working with Clinical Evidence editors to ensure that the final text meets epidemiological and style standards.

- Updating the text every six months using any new, sound evidence that becomes available. The Clinical Evidence in-house team will conduct the searches for contributors; your task is simply to filter out high quality studies and incorporate them in the existing text.

- To expand the topic to include a new question about once every 12-18 months.

If you would like to become a contributor for Clinical Evidence or require more information about what this involves please send your contact details and a copy of your CV, clearly stating the clinical area you are interested in, to Klara Brunnhuber (kbrunnhuber@ bmigroup.com).

\section{Call for peer reviewers}

Clinical Evidence also needs to recruit a number of new peer reviewers specifically with an interest in the clinical areas stated above, and also others related to general practice. Peer reviewers are healthcare professionals or epidemiologists with experience in evidence-based medicine. As a peer reviewer you would be asked for your views on the clinical relevance, validity, and accessibility of specific topics within the journal, and their usefulness to the intended audience (international generalists and healthcare professionals, possibly with limited statistical knowledge). Topics are usually 1500-3000 words in length and we would ask you to review between 2-5 topics per year. The peer review process takes place throughout the year, and our turnaround time for each review is ideally 10-14 days.

If you are interested in becoming a peer reviewer for Clinical Evidence, please complete the peer review questionnaire at www.clinicalevidence.com or contact Klara Brunnhuber (kbrunnhuber@bmigroup.com). 